\title{
¿Se cumple la Directiva de Servicios en Andalucía?
}

\author{
Ricardo Rivero Ortega \\ Profesor titular de Derecho Adminiatrativo. \\ Universidad de Salamanca
}

\begin{abstract}
SUMARIO: I. EL INGENTE ESFUERZO NORMATIVO DE LA TRANSPOSICIÓN DE LA DIRECTIVA DE SERVICIOS EN PLENA CRISIS. II. LA TRANSPOSICIÓN EN EL ESTADO AUTONÓMICO. II. LAS OPCIONES NORMATIVAS ESTRATÉGICAS EN LA COMUNIDAD AUTÓNOMA DE ANDALUCÍA. IV. MEDIDAS DE SIMPLIFICACIÓN ADMINISTRATIVA. V. BALANCE: UN GRAN TRABAJO REALIZADO; MUCHO TRABAJO POR HACER
\end{abstract}

\section{RESUMEN}

Este trabajo analiza el grado de cumplimiento de las exigencias de la transposición de la Directiva 2006/123/CE, del Parlamento Europeo y del Consejo, de 12 de diciembre de 2006, relativa a los Servicios en el Mercado Interior, en la Comunidad Autónoma de Andalucía, después del ingente esfuerzo realizado para adaptar numerosas normas y reglamentos del Ordenamiento autonómico a sus principios. Tras exponer el iter de las reformas efectuadas en el nivel estatal y andaluz, se exponen también las medidas de simplificación administrativa y régimen local, para concluir señalando tanto lo conseguido como lo que todavía está por hacer.

Palabras clave:

Directiva de Servicios, Ordenamiento andaluz, regulación económica, simplificación administrativa.

\section{ABSTRACT}

This work deals with the implementation of the Services Directive in Andalusia, after the great effort to adapt many norms and regulations to its principles. The reforms in the state and andalusian level are described, an also the administrative simplifications and local government measures are explained, to conclude with an emphasis on the achievements and the tasks that are not finished. 
Keywords:

Services Directive, andalusian Law, economic regulation, administrative simplification.

\section{EL INGENTE ESFUERZO NORMATIVO DE LA TRANSPOSICIÓN DE LA DIRECTIVA DE SERVICIOS EN PLENA CRISIS}

Pocas cuestiones han dado lugar a tanto debate jurídico-administrativo en los últimos tiempos como la transposición de la Directiva de Servicios, principal protagonista de las argumentaciones expuestas en los dos últimos encuentros de la Asociación Española de Profesores de Derecho Administrativo (AEDPA), respectivamente celebradas en San Fernando (Cádiz) y Palma de Mallorca en 2010 y $2011^{1}$. Con independencia de los distintos puntos de vista sobre su importancia y alcance - para todos los gustos- ha de reconocerse que el revuelo suscitado por su impacto en nuestro Ordenamiento jurídico ha sido mayúsculo ${ }^{2}$.

Transponer la Directiva de Servicios en España ha exigido un número de páginas en los boletines oficiales incomparable con el perceptible en cualquier otro país de la Unión Europea. Nuestro Estado descentralizado complejo, con un reparto muy farragoso de los poderes de decisión normativa y ejecutiva en al menos tres niveles (Estado, Comunidad Autónoma, municipio) multiplica

${ }^{1}$ En la reunión de 2010, con motivo de la exposición de las ponencias sobre la libertad de comercio (elaboradas por Joaquín TORNOS MAS y Ricardo RIVERO ORTEGA); en la de 2011, al analizar las relativas al Derecho de la crisis económica, presentadas por Antonio EMBID IRUJO y Alba NOGUEIRA LÓPEZ.

${ }^{2}$ José Carlos LAGUNA DE PAZ sostuvo tempranamente la idea de que estábamos ante una mera codificación de la jurisprudencia previa del Tribunal de Justicia y los principios del Derecho europeo, en su aportación titulada "Directiva de Servicios: el estruendo del parto de los montes", El Cronista del Estado Social y Democrático de Derecho, núm. 6, 2009. Con otro punto de vista, cuestionan la mutación constitucional derivada a su juicio de la norma europea Tomás DE LA QUADRA SALCEDO y Luciano PAREJO ALFONSO. Vid. DE LA QUADRA-SALCEDO FERNÁNDEZ DEL GASTILLO, Tomás (Dir.), El mercado interior de servicios en la Unión Europea. Estudios sobre la Directiva 123/2006/CE relativa a los servicios en el mercado interior, Marcial Pons, Madrid, 2009. PAREJO ALFONSO, Luciano, "La desregulación de los servicios con motivo de la Directiva Bolkstein”, El Cronista del Estado Social y Democrático de Derecho, núm. 6, 2009. Quien más relevancia ha reconocido a la Directiva por sus repercusiones en nuestro Ordenamiento quizás ha sido Tomás-Ramón FERNÁNDEZ RODRÍGUEZ, "Un nuevo Derecho administrativo para el mercado interior europeo", Revista Española de Derecho europeo, núm. 22, 2007. 
primero por 17 y luego por más de 8000 los pasos a dar para cumplir hasta sus últimas consecuencias los preceptos del Derecho comunitario (complejidades que trascienden esta norma en concreto, como puso de manifiesto el Informe del Consejo de Estado sobre la inserción del Derecho europeo en el Ordenamiento español, de 14 de febrero de 2008) ${ }^{3}$.

Buena prueba del correcto diagnóstico de las dificultades es que todavía estamos en trance de culminar el proceso, a pesar de todo lo que se ha hecho ya. A finales del año pasado, se podía leer la página web del Ministerio de Economía el Informe sobre la Transposición de la Directiva de Servicios de 29 de abril de 2010, cuyas cifras demuestran la magnitud de la operación realizada: en el nivel del Estado, se computaban los cambios en 50 leyes y 118 reales decretos, con el balance de la eliminación de 116 autorizaciones; y en el nivel autonómico, se daba cuenta de la reforma de 199 leyes y 546 decretos, con la consecuencia de haber "barrido" 633 autorizaciones en total ${ }^{4}$.

A pesar de todo este esfuerzo, no logramos evitar la impresión de que una mayor proactividad e implicación de las autoridades autonómicas y locales desde un principio -en la línea recomendada en el año 2005 por el Comité de las Regiones- podría haber facilitado la realización del objetivo en todos los niveles. Y es que no deja de ser significativo que todavía en el año 2011 se presente la culminación de esta tarea como una de las claves para la reactivación de la economía, en plena discusión sobre la reforma aún pendiente de los colegios profesionales. El reproche de la lentitud en la adopción de algunas de las reformas estructurales derivadas de la transposición de la Directiva es difícil de evitar, particularmente si se acepta su conexión con la posible mejora de la situación económica ${ }^{5}$.

Por supuesto, es inevitable el debate sobre la oportunidad de acometer este tipo de modificaciones, que afectan a intereses negativamente, en un esce-

${ }^{3}$ Vid. RIVERO ORTEGA, Ricardo, "Reformas administrativas para 2010: La difícil transposición de la Directiva de Servicios en España”, Revista Aragonesa de Administración Pública, 2010.

${ }^{4}$ Vid. RIVERO ORTEGA, Ricardo, "La transposición de la Directiva de Servicios: panorámica general y balance de su transposición en España”, Noticias de la Unión Europea, Junio 2011.

${ }^{5}$ Para contrastar con una perspectiva más positiva y optimista del trabajo realizado, teniendo presente el proceso interno de las Administraciones públicas, Vid. FERNÁNDEZ BARJAU, Blanca/MARTÍNEZ ALBALADEJO, Teresa, "El proceso de transposición de la Directiva de Servicios en España: hacia una reforma", Información Comercial Española-Boletín Económico del ICE, núm. 2990, 2010. 
nario de recesión y pérdida masiva de puestos de trabajo. Pero también debe recordarse el muy largo período de tiempo concedido para la transposición (tres años) y la recurrente crítica de algunos destacados medios de información económica internacional (Financial Times, The Economist...) contra la lentitud en los procesos de cambio estructural español, periódicos extranjeros que también llegaron a detenerse en el detalle de la reforma laboral o las duplicidades y exceso del Estado Autonómico ${ }^{6}$.

\section{LA TRANSPOSICIÓN EN EL ESTADO AUTONÓMICO}

Los problemas derivados de la compleja multidescentralización española para cumplir la Directiva de Servicios no se le escapan a ninguno de los autores que han analizado este proceso ${ }^{7}$. Marco problemático que se acentúa toda vez que los títulos constitucionales invocables por el Estado para llevar a cabo la transposición $(149.1 .1 ; 149.1 .13 ; 149.1 .18)$ no resultan suficientes a juicio de algunos expertos para invadir presuntas competencias autonómicas en la regulación de sectores que les corresponden por dictado estatutario ${ }^{8}$.

Muy relevante desde mi punto de vista es en este sentido el contenido del Dictamen del Consejo de Estado sobre el Anteproyecto de Ley de Libre Acceso a las Actividades de Servicios y su Ejercicio, documento en el que el supremo órgano consultivo del Gobierno señala nada menos que al artículo 150 de la Constitución española para llevar a cabo la operación pretendida por el texto que se informa, al que se dota positivamente de carácter básico pero que aún

${ }^{6} \mathrm{Al}$ respecto, Vid. RIVERO ORTEGA, Ricardo, "Qué reformas estructurales”, en Libro Homenaje al Profesor Gaspar Ariño Ortiz, Instituto de Estudios de la Regulación, Madrid, 2011.

7 Vid. JIMÉNEZ ASENSIO, Rafael, La incorporación de la Directiva de Servicios al Derecho interno, IVAP, Oñate, 2010.

${ }^{8}$ Vid. DE LA QUADRA-SALCEDO JANINI, Tomás, "Estado autonómico y transposición de la Directiva de Servicios", en VICENTE BLANCO, Dámaso-Javier/RIVERO ORTEGA, Ricardo (Dirs.), Impacto de la transposición de la Directiva de Servicios en Castilla y León, CES, Valladolid, 2010. A juicio de URRUTIA LIBARONA “....la Directiva de Servicios afecta a multitud de competencias sectoriales exclusivas de las Comunidades Autónomas, cuya naturaleza no puede verse alterada a través de una ley transversal declarada básica. Esto último no puede convertir en competencias compartidas lo que de acuerdo con la Constitución y con los Estatutos de Autonomía no lo son", URRUTIA LIBARONA, Íñigo, Marco jurídico del libre acceso a las actividades de servicios y su ejercicio en la Comunidad Autónoma del País Vasco, IVAP, Oñate, 2010, p.159. 
ha suscitado dudas competenciales desde el punto de vista de algunos intérpretes $^{9}$. No es extraño por ello que parte de la doctrina constitucional se sume a las indicaciones realizadas por el Consejo de Estado, en el sentido de preferir el recurso a la Ley de Armonización ${ }^{10}$.

Pero en cualquier caso este debate se ha visto superado temporalmente por la marea normativa posterior, ciertamente sin excepciones en la misma línea pragmática de transposición y no cuestionamiento de la estrategia estatal. La ausencia de recursos de inconstitucionalidad frente a la Ley de Libre Acceso a las Actividades de Servicios y su Ejercicio (Ley Paraguas) resulta en todo caso elocuente; y la mínima reacción frente a la Ley de modificación de diversas leyes para su adaptación a la anterior (Ley Ómnibus) también nos pone delante del muy relativo calibre del conflicto competencial ${ }^{11}$.

Las Comunidades Autónomas también han aprobado las modificaciones correspondientes de sus propias normas, imprescindibles para realizar las exigencias de la Directiva en sectores sobre los que ejercen competencias relevantes, como el comercio o el turismo, y no puede señalarse actitud de resistencia explícita alguna a la implementación de los principios simplificadores, ni a la

9 "Lo menos que se puede decir es que la ubicación que pretende tener la Ley Paraguas en el contexto del sistema normativo es complicada. De ahí que antes afirmara que esta modalidad de transposición crea, a mi juicio, más incógnitas que resuelve problemas", SALVADOR ARMENDÁRIZ, Ma Amparo, "La Directiva de Servicios y su transposición: ¿Una ocasión para repensar el derecho a la libertad de empresa?", en RIVERO ORTEGA, Ricardo (Dir.), Mercado europeo y reformas administrativas. La transposición de la Directiva de Servicios en España, Cívitas, Madrid, 2010.

10 "Los argumentos manejados por el Consejo de Estado en esta dirección (en síntesis, la coexistencia de potestades normativas de diverso alcance, la complejidad intrínseca de la transposición de la Directiva de Servicios y el riesgo cierto de que se produzcan disfunciones en dicha labor) son dificilmente cuestionables", MATIA PORTILLA, Francisco Javier, "La transposición de la Directiva de Servicios en el Estado central y en la Comunidad Autónoma de Castilla y León (un estudio de fuentes del Derecho)", en VICENTE BLANCO, Dámaso-Javier/RIVERO ORTEGA, Ricardo (Dirs.), Impacto de la transposición de la Directiva de Servicios en Castilla y León, Valladolid, 2010, p.160.

11 El Gobierno de la Generalidad de Cataluña interpuso recurso de inconstitucionalidad frente al artículo 5.5, la Disposición Transitoria Cuarta y la Disposición Final Primera de la Ley 25/2009, de 22 de diciembre, de modificación de diversas leyes para su adaptación a la Ley sobre el Libre Acceso a las Actividades de Servicios y su Ejercicio. El Gobierno de España, por su parte, ha interpuesto recurso de inconstitucionalidad contra la transposición en la Comunidad Autónoma de Galicia. 
sustitución de autorizaciones por otras técnicas, ni a las nuevas formas de regulación. En general, se observa la común aceptación de la Directiva en gobiernos de todo signo, más allá de las polémicas doctrinales a favor o en contra de sus previsiones:

Aragón sería un primer buen ejemplo de esta tendencia, anticipada por cierto con la aprobación del Decreto-Ley 1/2008, de 30 de octubre, de medidas administrativas urgentes para facilitar la actividad económica en Aragón. Y posteriormente mediante la aprobación del Decreto-Ley 1/2010, de 27 de abril, del Gobierno de Aragón, de modificación de diversas leyes de la Comunidad Autónoma de Aragón para la transposición de la Directiva 2006/123/CE del Parlamento Europeo y del Consejo, de 12 de diciembre de 2006, relativa a los servicios en el mercado interior ${ }^{12}$.

Baleares aprobó la Ley 8/2009, de 16 de diciembre, de reforma de la Ley 11/2001, de 15 de junio, de ordenación de la actividad comercial en las Illes Balears para la transposición de la Directiva 2006/123/CE del Parlamento Europeo y del Consejo, de 12 de diciembre de 2006, relativa a los servicios en el mercado interior. Posteriormente, en 2010 aprobaría la Ley 12/2010, de 12 de noviembre, para la modificación de numerosas leyes con el objeto de la transposición (incluyendo desde servicios profesionales hasta medidas administrativas).

Canarias aprobó la Ley 12/2009, de 16 de diciembre, reguladora de la licencia comercial. Y recientemente ha aprobado la Ley 8/2011, de 8 de abril, por la que se modifica la Ley 4/1994, de Ordenación de la actividad comercial de Canarias.

Cantabria ha aprobado las leyes 2/2010, de 4 de mayo, para la modificación de la Ley 1/2002, de 26 de febrero, del Comercio de Cantabria y de otras normas complementarias para su adaptación a la Directiva 2006/123/CE, del Parlamento Europeo y del Consejo, de 12 de diciembre de 2006, relativa a los Servicios en el Mercado Interior, y 3/2010, de 20 de mayo, por la que se modifica la Ley 1/2001, de 16 de marzo, de Colegios Profesionales de Cantabria, para su adaptación a la Ley sobre el libre acceso a las actividades de servicios y su ejercicio.

12 Vid. El impacto de la Directiva Bolkstein y la reforma de los servicios en el Derecho administrativo, número monográfico de la Revista Aragonesa de Administración Pública coordinado por Elisa MOREU, 2011 . 
Castilla-La Mancha aprobó la Ley 7/2009, de 17 de diciembre, de modificación de diversas Leyes para su adaptación a la Directiva 2006/123/CE, de 12 de diciembre, del Parlamento Europeo y del Consejo, relativa a los Servicios en el Mercado interior. Se introducen cambios en las Leyes de calidad agroalimentaria, de montes y gestión forestal sostenible, de vías pecuarias, de ordenación del turismo y de actividades feriales de esta Comunidad Autónoma. Se suprimen con estas modificaciones varios regímenes autorizatorios, introduciendo en otros los principios de la Directiva (publicidad, objetividad, imparcialidad, transparencia y concurrencia) en su concesión.

Castilla y León aprobó el Decreto-Ley 3/2009, de 23 de diciembre, de Medidas de Impulso de las Actividades de Servicios en Castilla y León, inclusivo tanto de medidas generales (Administración pública, consumidores y usuarios, servicios profesionales) como de las principales reformas sectoriales (servicios comerciales, servicios turísticos, servicios medioambientales, espectáculos y juego, carreteras, centros educativos, mediación familiar, sanidad animal, salud pública, seguridad industrial, servicios sociales, etc. $)^{13}$.

Cataluña, tras la aprobación del Decreto-Ley 1/2009, de ordenación de los equipamientos comerciales, ha optado por la delegación legislativa, aprobando la Ley 5/2010, de 26 de marzo, de bases de delegación en el Gobierno de la potestad legislativa para la adecuación de normas con rango de Ley a la Directiva 2006/123/CE, del Parlamento y del Consejo, de 12 de diciembre de 2006, relativa a los servicios en el mercado interior ${ }^{14}$.

Extremadura aprobó la Ley 7/2010, de 19 de julio, de modificación de la Ley 3/2002, de 9 de mayo, de Comercio, y la Ley 8/2010, de 19 de julio, de modificación de la Ley 3/2002.

${ }^{13}$ RIVERO ORTEGA, Ricardo, "La transposición de la Directiva de Servicios en Castilla y León: valoración crítica de la estrategia de transposición y las medidas adoptadas", en VICENTE BLANCO, Dámaso-Javier/RIVERO ORTEGA, Ricardo (Dirs.), Impacto de la transposición de la Directiva de Servicios en Castilla y León, CES, Valladolid, 2010.

${ }^{14}$ La Revista Catalana de Derecho Público dedica su número 42, de junio de 2011, a los Retos y desafios de la Directiva de Servicios, con aportaciones de Belén NOGUERA DE LA MUELA, Francina ESTEVE GARCÍA, Mercedes FUERTES LÓPEZ, Juan Ramón FERNÁNDEZ TORRES, Ricardo RIVERO ORTEGA, Tomás FONT I LLOVET, Silvia DEL SAZ CORDERO, Helena VILLAREJO GALENDE, Tomás DE LA QUADRA-SALCEDO JANINI, José Manuel PÉREZ FERNÁNDEZ y Marc CASAS I RONDONÍ. 
Galicia ha aprobado la Ley 1/2010, de 11 de febrero, de modificación de diversas Leyes de Galicia para su adaptación a la Directiva 2006/123/CE, del Parlamento Europeo y del Consejo, de 12 de diciembre de 2006, relativa a los servicios en el mercado interior. Modifica la Ley de Administración local de Galicia, con el fin de facilitar el acceso a la ventanilla única electrónica; también introduce reformas en materia de colegios profesionales, industria, actividades feriales, servicios ambientales y de la agricultura, servicios culturales y turísticos, etc.

Madrid aprobó con gran despliegue informativo la Ley 8/2009, de 21 de diciembre, de Medidas Liberalizadoras y de Apoyo a la Empresa Madrileña, una norma que lleva los principios y exigencias de la Directiva de Servicios hasta consecuencias no asumidas por muchas otras Comunidades, como la desaparición de la licencia comercial para las grandes superficies.

Murcia aprobó la Ley 12/2009, de 11 de diciembre, por la que se modifican diversas Leyes para su a adaptación a la Directiva 2006/123/CE, de 12 de diciembre, del Parlamento Europeo y del Consejo, relativa a los Servicios en el Mercado interior. Las Leyes modificadas son las de turismo, juegos y apuestas, deporte, artesanía, comercio minorista y ferias.

Navarra aprobó la Ley Foral 6/2010, de 6 de abril, de modificación de diversas Leyes forales para su adaptación a la Directiva 2006/123/CE, relativa a los servicios en el mercado interior, y Ley Foral 6/2010, de 6 de abril, de modificación de diversas Leyes forales para su adaptación a la Directiva 2006/123/CE, relativa a los servicios en el mercado interior.

El País Vasco reformó en el año 2008 su Ley del Turismo, pero no explicita entre los motivos de esta modificación, operada por la Ley 16/2008, de 23 de diciembre, la adaptación a la Directiva de Servicios. Sí lo hace en cambio la Ley $7 / 2008$, de 25 de junio, de segunda modificación de la Ley de la actividad comercial. En marzo de 2010 se presentó un Anteproyecto de Ley para la transposición que contemplaba la modificación de numerosas leyes vascas (del juego, de museos, de industria, del turismo, de ordenación vitivinícola, de protección del medio ambiente, de profesiones tituladas, de fundaciones, de ordenación farmacéutica, de servicios sociales, de mediación familiar y de urbanismo $)^{15}$.

15 Vid. URRUTIA LIBARONA, Íñigo, Marco jurídico del libre acceso a las actividades de servicios y su ejercicio en la Comunidad Autónoma del País Vasco, IVAP, Oñate, 2010. 
Sobre este anteproyecto de ómnibus vasca se estaba informando todavía a finales del año pasado

Valencia aprobó la Ley 12/2009, de 23 de diciembre, de medidas fiscales, de gestión administrativa y financiera y de organización de la Generalitat, reformando entre otras leyes las de turismo, comercio, ordenación farmacéutica, espectáculos públicos, protección de animales de compañía, etc.

A pesar, pues, de los debates doctrinales y las dificultades, en plena crisis, la agenda legislativa autonómica ha estado marcada durante los años 2009 y 2010 por la aprobación de estos textos, que no han dado lugar a excesivos enfrentamientos políticos en la España de las Autonomías porque la mayoría de los responsables públicos estaban trabajando en las reformas estructurales que consideraban podrían servir para dinamizar la economía española, demostrando que cuando el Estado autonómico debe moverse al unísono, puede hacerlo, pues los resultados comparativos entre comunidades no han sido ni tan dispares, ni tan disfuncionales. La coordinación, en la práctica, por fin ha funcionado razonablemente, y esto es positivo en mi opinión.

\section{LAS OPCIONES NORMATIVAS ESTRATÉGICAS EN LA COMUNIDAD AUTÓNOMA DE ANDALUCÍA}

La Comunidad Autónoma de Andalucía acomete la transposición de la Directiva de Servicios tras la aprobación de un nuevo Estatuto de Autonomía que pone al día su régimen de autogobierno. Lo hace por tanto con un nivel máximo y renovado de competencias, que permiten a sus instituciones propias tomar el mayor número de decisiones sobre las materias afectadas por el Derecho europeo, incluyendo por supuesto la reforma de sus procedimientos administrativos ${ }^{16}$.

Según la información que podemos encontrar en la propia web institucional de la Junta de Andalucía, el 24 de marzo de 2009 autorizó el Consejo de Gobierno iniciar los trámites del anteproyecto de Ley dirigido a la transposición en Andalucía de la Directiva 2006/123/CE, relativa a los servicios en el

16 Vid. BALAGUER CALLEjÓN, Francisco/CÁMARA VILLAR, Gregorio/RODRÍGUEZ, Ángel/MONTILLA MARTOS, José Antonio/RUIZ ROBLEDO, Agustín, El nuevo Estatuto de Autonomía de Andalucía, Tecnos, 2007. 
mercado interior. En tal anteproyecto se planteaba reformar las siguientes leyes: Ley 12/1999, de 15 de diciembre, del Turismo; Ley 8/2001, de 12 de julio, de Carreteras de Andalucía; Ley 8/2007, de 5 de octubre, de Museos y Colecciones museográficas de Andalucía; Ley 14/2007, de 26 de noviembre, del Patrimonio Histórico de Andalucía; y Ley 2/1986, de 19 de abril, del Juego y Apuestas de la Comunidad Autónoma de Andalucía. El 8 de abril de 2009 se anunció el trámite de información pública de este anteproyecto.

De acuerdo con la Exposición de Motivos de este texto, que refleja la primera opción del Gobierno de la Comunidad de Autónoma de Andalucía en cuanto a la forma y el fondo de la transposición, la Ley del Turismo debía reformarse en el sentido de sustituir las autorizaciones por declaraciones responsables, sustituyendo los controles previos por controles posteriores (actuación inspectora); en la Ley de Carreteras, se pretendía sustituir la autorización previa para la instalación de rótulos de establecimientos mercantiles por una mera comunicación previa; en la Ley de Museos, el procedimiento autorizatorio para su disolución se sustituye por una comunicación previa, planteando asimismo una mera "notificación previa" para la salida de fondos museísticos; en la Ley de Patrimonio Histórico se proponía una modificación del régimen de la autorización para actividades arqueológicas preventivas; y en la Ley del Juego y Apuestas se suprimía la exigencia de autorización administrativa previa para la organización, celebración y desarrollo de combinaciones aleatorias con fines publicitarios o promocionales, siempre y cuando se tratara de actividades en las que la participación del público fuera gratuita y no existiera sobreprecio o tarificación adicional.

En este Anteproyecto se recogían pues relevantes modificaciones legales, pero a todas luces insuficientes para llevar a cabo el considerable desafío de la transposición, como las presentaciones de responsables de la propia Junta por aquellas fechas mostraban. Así, por ejemplo, en documentos accesibles firmados por Javier VISUS, se señala que en la fase de identificación realizada por la Administración autonómica se detectaron 45 normas con rango de Ley para reformar, 176 normas con rango de Decreto y 103 con rango de órdenes y resoluciones, con un balance total tras la suma de estas cifras de 324 normas identificadas ${ }^{17}$.

17 Vid. VISUS ARBESÚ, Javier, "La transposición de la Directiva de Servicios en Andalucía", en

http://www.juntadeandalucia.es/gobernacionyjusticia/opencms/portal/com/bin/portal/AdministracionLocal/Publicaciones/jornadas_trasposic_/p_22.pdf 
En cuanto a los procedimientos, esta misma ponencia nos ofrecía datos elocuentes, fechados en enero de 2009: 1042 procedimientos identificados por la Administración General del Estado; 548 procedimientos identificados en Galicia; y no muy lejos, en Andalucía, 530. La fase de evaluación se desarrolló a través de la aplicación informática SIENA, facilitada por el Ministerio de Economía y Hacienda (que lideró el proceso) y consistente en cuestionarios relativos a la afectación de los procedimientos por el ámbito de aplicación de la Directiva, su necesidad, proporcionalidad y no discriminación. La evaluación de las normas con rango legal se inicia conforme a esta información a la altura de noviembre de 2008; posteriormente se iniciaría la evaluación de las normas reglamentarias (hay que entender que ya en 2009, con menos de un año para la transposición).

Esta ponencia nos ofrece también conclusiones sobre la evaluación realizada, diciéndonos que en las leyes afectadas se detectaron 64 procedimientos incluidos en el ámbito de aplicación de la Directiva de Servicios, de los cuales 40 resultarían incompatibles con la misma por no ser necesarios, proporcionales o no discriminatorios. Se destacaban además los sectores en los que se daban tal es situaciones: turismo, comercio y deportes. En cambio, 14 se consideraban compatibles por ser necesarios, proporcionales y no discriminatorios. La lista de leyes que debían ser reformadas coincide con las incluidas en el Anteproyecto que antes hemos comentado, más las relativas al sector comercio que se tramitaron por otra vía: Ley 1/1996, de 10 de enero de 1996, del Comercio Interior de Andalucía; Ley 9/1988, de 25 de noviembre, del Comercio Ambulante; Ley 3/1992, de 22 de octubre, de Ferias Comerciales Oficiales de Andalucía.

El retraso de las leyes aprobadas por el Estado, que no verán la luz hasta los últimos días del año 2009, en el límite del período de transposición, probablemente explica que se optara en Andalucía (como en otras Comunidades Autónomas, así también en Castilla y León) por utilizar la figura del Decreto-Ley. La extraordinaria y urgente necesidad se vincularía al plazo marcado por el Derecho europeo, pero como nos explica también la Exposición de motivos del Decreto-Ley $3 / 2009$, a un potencial riesgo de inseguridad jurídica, por el discutible efecto derogatorio de la Ley 17/2009, de 23 de noviembre. Las explicaciones ofrecidas por el poder normativo andaluz en este caso son plausibles, pero muestran la falta de sintonía plena en el manejo de los tiempos de las reformas del legislador estatal y los autonómicos.

$\mathrm{Al}$ fin, los principales resultados de cambio del Ordenamiento andaluz dentro del plazo lo ofrecerá Decreto-Ley 3/2009, de 22 de diciembre, por el 
que se modifican diversas leyes para la transposición en Andalucía de la Directiva 2006/123/CE, de 12 de diciembre de 2006, del Parlamento Europeo y del Consejo, relativa a los servicios en el mercado interior. Este Decreto-Ley reformaría las siguientes leyes: Ley 1/1996, de 10 de enero de 1996, del Comercio Interior de Andalucía; Ley 9/1988, de 25 de noviembre, del Comercio Ambulante; Ley 3/1992, de 22 de octubre, de Ferias Comerciales Oficiales de Andalucía; Ley 12/1999, de 15 de diciembre, del Turismo; Ley 8/2001, de 12 de julio, de Carreteras de Andalucía; Ley 8/2007, de 5 de octubre, de Museos y Colecciones museográficas de Andalucía; Ley 14/2007, de 26 de noviembre, del Patrimonio Histórico de Andalucía; y Ley 2/1986, de 19 de abril, del Juego y Apuestas de la Comunidad Autónoma de Andalucía; Decreto Legislativo $1 / 2009$, de 1 de septiembre, por el que se aprueba el Texto Refundido de las Disposiciones dictadas por la Comunidad Autónoma de Andalucía en materia de tributos cedidos; Ley 22/2007, de 18 de diciembre, de Farmacia de Andalucía; Ley 2/2007, de 27 de marzo, de fomento de las energías renovables y del ahorro y eficiencia energética de Andalucía; Ley 2/1989, de 18 de julio, por la que se aprueba el inventario de espacios naturales protegidos de Andalucía; Ley 2/1992, de 15 de junio, Forestal de Andalucía; Ley 5/1999, de 29 de junio, de Prevención y lucha contra los incendios forestales; Ley 8/1999, de 27 de octubre, de Régimen Jurídico del Espacio Natural de Doñana y Ley 8/2003, de 28 de octubre, de la flora y la fauna silvestres.

Más tarde, la Ley 3/2010, de 21 de mayo, que modifica diversas leyes para la transposición en Andalucía de la Directiva 2006/123/CE, de 12 de diciembre de 2006, del Parlamento Europeo y del Consejo, relativa a los servicios en el mercado interior, reafirmaría las reformas del Decreto-Ley 3/2009, de 22 de diciembre e introduciendo otras en un sector clave como es el comercio $^{18}$.

Así, se modifican las leyes 1/1996, de 10 de enero, del Comercio interior de Andalucía; la Ley 9/1988, de 25 de noviembre, del Comercio Ambulante; y la Ley 3/1992, de 22 de octubre, de Ferias Comerciales Oficiales de Andalucía. La reforma comercial andaluza introduce los criterios territoriales, urbanísticos y ambientales en la planificación de la ubicación de establecimientos comerciales (Plan de Establecimientos Comerciales), considerando grandes superficies las que superen los 2500 metros de superficie. Andalucía es una de las

18 Vid. VILLAREJO GALENDE, Helena (Dir.), La Directiva de Servicios y su impacto en el comercio europeo, Comares, Granada, 2009. 
pocas Comunidades Autónomas en las que desaparece la licencia autonómica para su instalación, cuya autorización corresponde tras la reforma a los municipios (de forma respetuosa con la autonomía local ${ }^{19}$ ), pero prevé en cambio un informe autonómico preceptivo de la Consejería competente en materia de comercio interior que puede producir efectos muy similares al del veto autorizatorio $^{20}$.

Los criterios de preferencia en cuanto a la localización de las grandes superficies comerciales minoristas se asocian a factores urbanísticos o ambientales, pero también insinúan en parte el constante afán de ordenar el desarrollo comercial. Así, las referencias al "planeamiento comercial" del artículo 26 (Estrategia de planificación), o el 28, cuando detalla el contenido del "Plan de Establecimientos Comerciales" (incluyendo el análisis del comercio interior de Andalucía). La relación de criterios del artículo 33, en fin, ofrece una mezcla de urbanismo y política comercial difícilmente disociable en algunos casos: por ejemplo, en su apartado f ("Contribución al mantenimiento de los espacios comerciales presentes en la ciudad, identificando itinerarios y ejes comerciales, garantizando su accesibilidad, potenciando su concentración y delimitando zonas de actuación específica para su mejora”); igualmente, en su apartado g ("integración en el tejido comercial urbano, especialmente en los espacios comerciales existentes").

Las modificaciones en comercio ambulante también merecen cierta atención, dado que sus cifras económicas en Andalucía son más que significativas (25.000 comerciantes registrados). Se mantiene la exigencia de autorización en este sector, invocando el dominio público como título de intervención, amén de otras imperiosas razones de interés general (orden público, protección de los consumidores, protección civil, salud pública, protección de los destinatarios de los servicios, del medio ambiente y del entorno urbano). Este planteamiento sintoniza con el de la Ley estatal, pero podría mantenerse la duda de si los objetivos perseguidos por el control previo no podrían alcanzarse igualmente con

19 Vid. MERINO ESTRADA, Valentín, "Los nuevos regímenes de autorizaciones comerciales y la autonomía local", Revista de Estudios Locales, núm.127, Febrero 2010. RIVERO ORTEGA, Ricardo, "La libertad de comercio", Actas del Congreso de la Asociación Española de Profesores de Derecho Administrativo, San Fernando, Febrero 2010.

${ }^{20}$ Vid. RIVERO ORTEGA, Ricardo, "Repercusiones económicas de la transposición de la Directiva de Servicios: en especial, su impacto en el sector comercio", Revista Aragonesa de Administración Pública, 2011. 
controles posteriores, al margen de la necesidad de reformar la normativa reguladora del dominio público para poder eliminar la exigencia de autorización, por supuesto ${ }^{21}$.

Más allá del comercio, conviene detenerse por su importancia estratégica en la reforma sobre el sector turístico, donde la opción predominante -también en Andalucía- parece haber sido la de sustituir las autorizaciones administrativas por declaraciones responsables. Digo que parece haber sido porque aunque así lo proclama la Exposición de Motivos de la Ley andaluza de transposición, y parece reflejarse en la nueva redacción del artículo 28 de la Ley de Turismo de Andalucía ("Libertad de establecimiento y de prestación de los servicios turísticos") la exigencia de una clasificación y su procedimiento aproximan en sus efectos sobremanera el presunto régimen de declaración responsable a los típicos esquemas autorizatorios, demostrando en la práctica las numerosas incógnitas manifestadas por la doctrina sobre el desenvolvimiento de figuras no tan nuevas que tienden a confundirse con las más tradicionales ${ }^{22}$.

El 31 bis se proyecta tanto sobre la construcción como sobre la ampliación o reforma de un establecimiento turístico. Para cualquiera de estas operaciones, amén de la preceptiva licencia municipal de obras (que eventualmente ahora también habría que replantear), se debe presentar una primera declaración responsable que el Ayuntamiento remite a la Consejería competente de la Administración autonómica para que ésta, en el plazo de un mes, pueda reformular en su caso la clasificación pretendida. Al respecto se dice que "Transcurrido el plazo señalado...sin que la Consejería hubiera comunicado o notificado objeciones se considerará conforme con el proyecto". Una vez finalizadas las obras, se hace preciso presentar una nueva declaración responsable sobre la adecuación de las mismas a la clasificación requerida. Nos encontramos, pues, ante dos declaraciones responsables superpuestas, la primera de las cuales además contempla la necesidad de esperar un mes una respuesta, una lógica difícilmente compatible con la figura misma.

No sólo el nuevo artículo 31 bis de la nueva Ley de Turismo, que contempla la consabida clasificación, sino también el 35, sobre inscripción en base a

${ }^{21}$ Vid. SOLA TEYSSEIRE, Javier, "Notas sobre la ordenación legal de la venta ambulante", Revista CIE, 1986. Del mismo autor, Evolución histórica de la intervención administrativa sobre el comercio interior y la libertad de empresa comercial, Universidad de Sevilla, 2001.

22 Vid. NUÑEZ LOZANO, Carmen, "Autorizaciones, declaraciones responsables y comunicaciones previas", Noticias de la Unión Europea, Junio 2011. 
una declaración responsable, demuestran un mantenimiento del status quo de la intervención administrativa previa considerable. Muy pocos prestadores se ven realmente beneficiados por la relativa desaparición de tales controles, que seguirán protagonizando (aunque ya no con el nombre de autorizaciones) las intervenciones administrativas sobre el sector turístico.

No puede decirse sin embargo que el legislador andaluz no desee extraer consecuencias de la transposición de la Directiva de Servicios, pues ha extendido sus proyecciones más allá de las normas sectoriales referenciadas, alcanzando también al régimen local autonómico (algo que pocas Comunidades Autónomas han hecho de momento, salvo Andalucía y Navarra). La LAULA (Ley de Autonomía Local de Andalucía), con voluntad de realizar los principio de buena regulación del Derecho europeo, se anticipa a medidas que después encontramos en la Ley de Economía Sostenible, Ley 2/2011. Pero en el ámbito local la reforma de las ordenanzas sigue suscitando numerosas dudas y generará también controversias. La coordinación mediante un grupo de trabajo integrado por representantes de la Junta de Andalucía y las Diputaciones Provinciales para catalogar las ordenanzas necesitadas de cambios y proponer sus reformas concretas no parece haber sido suficiente.

\section{MEDIDAS DE SIMPLIFICACIÓN ADMINISTRATIVA}

La Directiva de Servicios no sólo exige revisar los procedimientos autorizatorios para, caso de ser desproporcionados, sustituirlos por técnicas de intervención menos gravosas de las libertades económicas. También propone una reconsideración de los procedimientos administrativos para mejorar su rendimiento evitando los excesivos costes que tienen que soportar las empresas ${ }^{23}$. Estos propósitos se traducen en medidas como la reducción de plazos, la descarga bucrocática y la realización de trámites por vía telemática, que son tan importantes para cumplir la Directiva de Servicios como las reformas puntuales de la regulación sectorial ${ }^{24}$.

23 Vid. VILLAREJO GALENDE, Helena, "Simplificación administrativa al servicio del mercado interior" en Retos y oportunidades para la transposición de la Directiva de Servicios. Libro Marrón del Círculo de Empresarios, 2009, MELLADO RUIZ, Lorenzo, "Directiva de Servicios y simplificación administrativa", Revista Noticias de la Unión Europea, 2011.

${ }^{24}$ Vid. RIVERO ORTEGA, Ricardo, "Simplificación administrativa y descarga burocrática: objetivos pendientes de la transposición de la Directiva de Servicios", Revista Catalana de Derecho Público, Junio 2011. 
El Plan de medidas de simplificación de procedimientos administrativos y agilización de los trámites de la Junta de Andalucía de enero de 2009 se propuso reducir a la mitad los tiempos en aquellos procedimientos de duración superior a los seis meses, un plazo extraordinariamente largo superado en muchos casos por previsiones de duración de más de un año. Poco posterior a este plan es el Decreto-Ley 1/2009, de 24 de febrero, por el que se adoptan medidas urgentes de carácter administrativo.

La Orden de 22 de febrero de 2010 modifica diversas órdenes anteriores para su adaptación al Plan de Medidas de Simplificación de Procedimientos Administrativos y Agilización de Trámites. Pocos días después se publica el Manual de Simplificación Administrativa y Agilización de Trámites de la Administración de la Junta de Andalucía.

Posteriormente se aprueba el Decreto-Ley 7/2010, de 28 de diciembre, de medidas para potenciar inversiones empresariales de interés estratégico para Andalucía y de simplificación, agilización administrativa y mejora de la regulación de actividades económicas en la Comunidad Autónoma de Andalucía. Una decisión del Gobierno andaluz que afirma perseverar en las medidas anteriores: "El presente Decreto-Ley viene a profundizar en la aplicación de los principios que inspiran la Directiva, extendiendo su alcance a todos los sectores económicos".

Entre las medidas de agilización, se incluye la previsión de un procedimiento urgente para la tramitación de los proyectos que sean calificados como de interés estratégico para Andalucía. Pero más importancia pueden tener, por su carácter general, las medidas previstas para facilitar la actividad de las pequeñas y medianas empresas (Pymes), consistentes en la sustitución de autorizaciones por declaraciones responsables y comunicaciones previas, en una línea anticipada también por la Directiva de Servicios que este Decreto-Ley extiendo más allá de su ámbito de aplicación, como antes hizo con su autodenominado "enfoque ambicioso" el Gobierno de España.

Deteniéndonos en el articulado concreto, para los proyectos de interés estratégico se contempla una reducción a la mitad de los plazos de tramitación, en una línea avanzada por otras Comunidades Autónomas (v.gr., Aragón) que por cierto poco añade a las posibilidades ya previstas en la normativa común de procedimiento administrativo (tramitación urgente). En nuestro Derecho se echa en falta una reconsideración de los plazos con carácter general, más allá del lugar común de que los proyectos especialmente importantes, por crear empleo y riqueza, debieran tramitarse con rapi- 
$\mathrm{dez}^{25}$. Decir que se reducen a la mitad los plazos en estos proyectos no supone añadir nada a lo que antes podía hacerse con el sentido común y la Ley $30 / 92$ en la mano.

Similar conclusión cabe extraer, la verdad, en torno a las previsiones del Capítulo III de este Decreto-Ley, dedicado a las llamadas "medidas de simplificación y mejora de la regulación". En sus artículos 13 y 14 se formulan sendas definiciones de declaración responsable y comunicación previa poco más detalladas que las incorporadas a la Ley 30/92 en la reforma efectuada mediante la llamada Ley Ómnibus (Ley de modificación de diversas leyes para su adaptación a la Ley de Libre Acceso a las Actividades de Servicios y su Ejercicio). No es extraño, aunque sí pone en evidencia al poder normativo andaluz, que la Disposición adicional segunda del Decreto-Ley confiese que "Los artículos 13, 14 y 15 del presente Decreto-Ley reproducen parcialmente el artículo 71 bis de la Ley 30/92, de 26 de noviembre, de Régimen Jurídico de las Administraciones Públicas y del Procedimiento Administrativo Común...”.

$\mathrm{Al}$ fin, pues todo queda casi en nada, salvo la promesa recurrente de seguir trabajando en la misma dirección, que nos avanza la Disposición Adicional Primera del Decreto Ley, dedicada a un nuevo Plan de Reducción de Cargas Administrativas a las Empresas: "El Consejo de Gobierno aprobará un nuevo "Plan de Reducción de Cargas Administrativas a las Empresas", en el plazo de seis meses desde la entrada en vigor de la presente norma, previa deliberación de la Comisión Delegada para Asuntos Económicos, que será elaborado en el marco del VII Acuerdo de Concertación Social de Andalucía por la Consejería competente en materia de Administración pública”.

¿Hacen falta otros seis meses para hacer lo que debiera haber hecho este Decreto-Ley? Esta forma de legislar, coincidente con la que ofrece la Ley de Economía Sostenible al problema del silencio administrativo, (hasta la aprobación del R.D.-Ley 8/2011) resulta frustrante, porque dice que quiere hacer lo que se reconoce que es necesario hacer, pero se deja para mañana lo que debiera hacerse hoy. A esto se le llama, cabalmente, procastinación.

Se procastina el cumplimiento de la Directiva de Servicios con el tenor de la Disposición Final Primera, dedicada a la adaptación de los procedimientos,

25 Vid. RIVERO ORTEGA, Ricardo, "Principio de celeridad", en SANTAMARÍA PASTOR, Juan Alfonso (Dir.), Los principios jurídicos del Derecho administrativo, La Ley, Madrid, 2010. 
que es donde se encuentra la clave de los plazos previsibles para la verdadera incorporación de los principios y técnicas de la norma europea al Ordenamiento andaluz de rango reglamentario. En el plazo de tres meses desde la entrada en vigor del Decreto-Ley (nos situamos en marzo de 2011), las consejerías competentes elevarán a la Comisión Delegada para Asuntos Económicos las propuestas de adaptación. Y después, en el plazo de seis meses desde la aprobación de la Comisión Delegada (nos situamos, pues, casi a finales de 2011) el Consejo de Gobierno aprobará los decretos o proyectos de Ley. Es decir, las normas se adaptarán a la Directiva dos años después de la finalización del plazo de transposición. Y esto lo dice una medida de agilización de los procedimientos administrativos.

No cambia demasiado esta crítica la posterior aprobación del 80/2010, de 30 de marzo, de simplificación de trámites administrativos y de modificación de diversos decretos para su adaptación al Decreto-Ley 3/2009, de 22 de diciembre, por el que se modifican diversas leyes para la transposición en Andalucía de la Directiva relativa a los servicios en el mercado interior. Básicamente se centra la modificación en el sector turístico ("la actividad del sector servicios con mayor importancia a nivel económico y de empleo total en Andalucía, constituyendo un recurso de primer orden en constante dinamismo").

Así, se modifican el Decreto 20/2010, de 29 de enero, de Turismo en el Medio Rural y Turismo Activo; el Decreto 202/2002, de 16 de julio, de oficinas de turismo y de la Red de Oficinas de Turismo de Andalucía; el Decreto 214/2002, de 30 de julio, regulador de los guías de turismo de Andalucía; el Decreto 301/2002, de 17 de diciembre, de agencias de viajes y centrales de reservas; el Decreto 164/2003, de 17 de junio, de ordenación de los campamentos de turismo; el Decreto 47/2004, de 10 de febrero, de establecimientos hosteleros; el Decreto 35/2008, de 5 de febrero, por el que se regula la organización y el funcionamiento del Registro de Turismo de Andalucía; y el Decreto 43/2008, de 12 de febrero, regulador de las condiciones de implantación y funcionamiento de campos de golf en Andalucía.

Una reforma reglamentaria de alcance, pero no tan intensa en lo que se refiere en concreto a la llamada simplificación administrativa, traducible en el allanamiento de procedimientos y trámites ${ }^{26}$.

26 Vid. NEVADO-BATALLA, Pedro, "Simplificación administrativa: el allanamiento de procedimientos y trámites para facilitar el acceso a una actividad de servicios y su ejercicio", en RIVERO ORTEGA (Dir.), Mercado europeo y reformas administrativas, 2010. 


\section{BALANCE: UN GRAN TRABAJO REALIZADO; MUCHO TRABAJO POR HACER}

No sería justo sin embargo dejar de reconocer el esfuerzo reformador de leyes, reglamentos y procedimientos que los responsables de la Comunidad Autónoma de Andalucía han realizado a lo largo de los años 2009, 2010 y la primera mitad del año 2011 para realizar las exigencias y principios de la Directiva de Servicios. El impulso dado a esta tarea y sus resultados son más que considerables, como muestran las múltiples reformas expuestas.

En comparación con el resto de las Comunidades Autónomas, de hecho, Andalucía presenta muchos cumplimientos de las exigencias de la Directiva de Servicios de los que sus responsables pueden sentirse satisfechos, desde este punto de vista. Y los procedimientos utilizados para llevara a cabo la adaptación, alternando la figura del Decreto-Ley para cumplir los plazos, y la posterior tramitación como proyecto de Ley para permitir el debate, resultan en mi opinión correctos.

En este sentido, las formas de la transposición contrastan significativamente con las empleadas, por ejemplo, en la Comunidad Autónoma de Castilla y León, donde recurriendo igualmente a la figura del Decreto-Ley, se rechazó de forma expresa en el Parlamento regional la petición de su tramitación como Proyecto de Ley por el procedimiento de urgencia, para permitir un mayor debate sobre sus contenidos concretos ${ }^{27}$.

Ahora bien, el proceso ha venido lastrado por desventajas similares a las observadas en el resto del territorio, comenzando por una estrategia de transposición "en cascada" liderada por el Ministerio de Economía y Hacienda que ha podido reducir el protagonismo de la muy relevante responsabilidad de las autoridades autonómicas ${ }^{28}$.

Una muestra de la relativa desinformación y los problemas generados por la falta de un mayor énfasis anticipado en las exigencias de la Directiva, que hubiera quizás contribuido a la proactividad en el cumplimiento, nos lo da la

${ }^{27}$ Vid. RIVERO ORTEGA, Ricardo, "La transposición de la Directiva de Servicios en Castilla y León: valoración crítica de la estrategia de transposición y las medidas adoptadas", en VICENTE BLANCO/RIVERO ORTEGA, 2010.

${ }^{28}$ Vid. RIVERO ORTEGA, Ricardo, "La transposición de la Directiva de Servicios en España", en Mercado europeo y reformas administrativas, Cívitas, Madrid, 2010. 
relación de leyes y reglamentos aprobados en la Comunidad Autónoma de Andalucía estando ya en vigor la norma europea: Ley 8/2007, de 5 de octubre, de Museos y Colecciones museográficas de Andalucía; Ley 14/2007, de 26 de noviembre, del Patrimonio Histórico de Andalucía;; Decreto Legislativo 1/2009, de 1 de septiembre, por el que se aprueba el Texto Refundido de las Disposiciones dictadas por la Comunidad Autónoma de Andalucía en materia de tributos cedidos; Ley 22/2007, de 18 de diciembre, de Farmacia de Andalucía; Ley 2/2007, de 27 de marzo, de fomento de las energías renovables y del ahorro y eficiencia energética de Andalucía.

Compensando en positivo, hay que decir que la Administración autonómica andaluza ofrece buenos resultados en lo referido a la implementación de la Administración electrónica, y particularmente cuando nos acercamos a la ventanilla única electrónica (www.eugo.es) y la información disponible. Entrar en este portal deja la impresión de lo constructivo que puede ser el proceso que se ha iniciado, a pesar de las deficiencias que pueden subsistir.

Una cuestión de gran importancia, por supuesto, es la relativa al grado de cumplimiento de las exigencias del Derecho europeo por parte de la reforma de la legislación comercial llevada a cabo en Andalucía, balance para el que contamos con una muy reciente Sentencia del Tribunal de Justicia, sobre la regulación comercial catalana, algunas de cuyas conclusiones serían también proyectables sobre la regulación andaluza. Toda vez que el Tribunal considera incompatible con el Derecho europeo prohibir la implantación de grandes superficies comerciales fuera de la trama urbana consolidada de varios municipios, y también declara la contravención del Plan territorial sectorial de equipamientos comerciales por establecer limitaciones de política económica superpuestas a las urbanísticas, habrá que plantearse si una aplicación radical de los criterios de preferencia del nuevo Derecho comercial andaluz no podría llevar a resultados distintos a los considerados vulneradores de la libertad de establecimiento por el Tribunal de Justicia ${ }^{29}$.

La cuestión, desde mi punto de vista, no está cerrada. Dependerá del diseño de la planificación comercial andaluza la insistencia o no en las condenas por violación del Derecho europeo. Y, más allá de esta cuestión jurídico-for-

${ }^{29}$ Vid. RIVERO ORTEGA, Ricardo, "Repercusiones económicas de la transposición de la Directiva de Servicios. Impacto sobre el sector comercial", Revista Aragonesa de Administración Pública, 2011. 
mal, también probablemente se producirán relevantes efectos del sesgo regulatorio por el que se opte sobre el desarrollo de la economía andaluza, dada la importancia del mercado interior para el progreso, que fue puesta de manifiesto brillantemente por Pedro ESCRIBANO COLLADO en un estudio ya clásico $^{30}$.

El sector clave del turismo, vital para la economía andaluza, explica una aceleración de las reformas reglamentarias, muchas de las cuales se producen en los primeros meses de 2010, con lo que no puede criticarse a Andalucía en este punto ${ }^{31}$. Todas las reformas autonómicas se han detenido también en este sector, uno de los más afectados por los cambios normativos, pero como se ha intentado mostrar en este trabajo, no todo lo que parecen cambios lo serán realmente si las declaraciones responsables representan un lastre burocrático tan intenso como las autorizaciones, con el agravante de ser más inseguras ${ }^{32}$.

Aún en abril de 2011, un informe presentado por la Escuela Andaluza de Economía reflejaba críticas a los frenos administrativos de la actividad empresarial, achacándose el $77 \%$ del papeleo a los procedimientos autorizatorios y las tasas y precios públicos asociados a los mismos. Este mismo estudio ponía de manifiesto la aceptación positiva de la tramitación on-line de los procedimientos frente a la existencia de ventanillas únicas (físicas, se entiende) ${ }^{33}$.

Algunos entes locales andaluces están recurriendo a todo tipo de subterfugios para mantener la exigencia licencias en ámbitos que podrían ser afectados por la Directiva, y últimamente también por la Ley de Economía Sostenible. La propuesta de modificación de ordenanzas promovida por la Federación Andaluza de Municipios y Provincias no evita estas malas prácticas, en contraste con iniciativas individuales que nos demuestran hasta qué punto pueden ser buenas las propuestas andaluzas, poniendo a disposición de cualquier inte-

${ }^{30}$ ESCRIBANO COLLADO, Pedro, El fomento del comercio interior, Instituto García Oviedo, Sevilla, 1978.

31 Vid. MELGOSA ARCOS, Javier, "Directiva de Servicios y Turismo: aproximación a la incidencia de la Directiva de Servicios en el marco jurídico del turismo español", Noticias Unión Europea, Junio 2011.

32 Vid. BERMEJO VERA, José/ESCARTÍN ESCUDÉ, Vicente, "El impacto de la Directiva de Servicios en el sector del turismo", Monografias de la Revista Aragonesa de Administración Pública, núm.12, 2011.

33 Vid. Diario Negocio, 10 de abril de 2011. 
resado modelos de formularios para declaraciones responsables y comunicaciones previas, una tarea que todavía no han realizado muchas organizaciones públicas con la obligación de hacerlo ${ }^{34}$.

La autoevaluación y evaluación crítica externa de lo que se ha hecho y sigue siendo necesario continuar haciendo es reconocida por otro lado por el propio Estado, más allá ahora de la Comunidad Autónoma de Andalucía, como demuestra la muy reciente Orden del Ministerio de Política Territorial y Administración Pública de 17 de marzo de 2011, por la que publica el Acuerdo del Consejo de Ministros de 4 de marzo de 2011 por el que se aprueban los programas y políticas públicas que serán objeto de evaluación por la Agencia Estatal de las Políticas Públicas y la Calidad de los Servicios en 2011.

Entre estos programas y políticas, se incluye una evaluación sobre las trabas administrativas para la creación de empresas, reconociendo que "parece conveniente realizar una nueva evaluación que se centre en el análisis de los efectos de las diferentes medidas implementadas, y en especial los debidos a las modificaciones derivadas de la transposición e implementación de la Directiva de Servicios, así como en el diagnóstico sobre las principales diferencias regulatorias y procedimentales existentes en los distintos ámbitos territoriales y sus efectos sobre la unidad de mercado". Que a renglón seguido también se contemple la encomienda a la Agencia para la elaboración de un informe relativo a las posibles duplicidades, solapamientos e ineficiencias del Estado Autonómico resulta a mi modo de ver sumamente elocuente, demostrándonos una vez más la necesidad de no incurrir en la autocomplacencia institucional en un mundo que evoluciona muy rápido, también en lo económico, planteándonos constantemente nuevos desafios.

La Administración autonómica de Andalucía puede asumirlos, como sus entes locales, porque cumplir plenamente la Directiva de Servicios no es una carga, sino la oportunidad de ponerse a la altura de las circunstancias y exigencias europeas, mejorando nuestro Derecho administrativo ${ }^{35}$.

34 BULLEjOS CALVO, Carlos, “Aplicación práctica de la Directiva de Servicios en las Ordenanzas locales. Formularios en las fases de identificación y evaluación de la normativa local afectada y sobre simplificación administrativa y ventanilla única", Revista Electrónica CEMCI, núm. 3, Abril-Junio 2009.

35 FERNÁNDEZ RODRÍGUEZ, Tomás-Ramón (2007). 